\title{
El porvenir de la población mundial: perspectivas demográficas, perspectivas éticas*
}

\author{
François Héran**
}

\section{Introducción}

$\mathrm{Al}$ inaugurar la cátedra Jean Bourgeois-Pichat con esta primera conferencia sobre el porvenir de la población mundial, quisiera decir de entrada cuánto agradecen los demógrafos franceses el homenaje que sus colegas mexicanos han querido hacer así a uno de los grandes pioneros de la demografía francesa e internacional, cuya personalidad, irradiante y modesta a la vez, ha dejado tantos buenos recuerdos en ambos lados del Atlántico.

Volveré dentro de un momento a la obra de Jean Bourgeois-Pichat. Permítaseme primero agradecer calurosamente a los responsables de las diferentes instituciones que se asociaron a la creación de esta cátedra: los señores Andrés Lira González, presidente de El Colegio de México, Jorge Santibáñez, presidente de El Colegio de la Frontera Norte, Michel Portais, representante en México del Institut de Recherche pour le Développement (IRD), André Quesnel, director del Centre de Population et Développement (Ceped), sin olvidar a la Embajada de Francia en México, representada por la señora Jeanne Texier y el señor Jean Franco.

Mi agradecimiento muy especial a Julieta Quilodrán Salgado, profesora de demografía en El Colegio de México, fiel amiga del INED y de Francia, que ha tenido un papel decisivo en esta hermosa iniciativa. Por último, quisiera aplaudir la presencia entre nosotros de Yolande Bourgeois-Pichat. Supongo que ella temía la perspectiva de un homenaje puramente formal, un tipo de ceremonia que no gustaba especialmente a su padre. Espero de todo corazón que al término de este encuentro a la vez amistoso e internacional, pueda aquilatar de nueva cuenta el aura que rodea la obra de su padre en el medio internacional de los demógrafos.

* Texto presentado en la inauguración de la cátedra Jean Bourgeois-Pichat, El Colegio de México, 29 de octubre de 2004. El autor agradece a Benoît Riandey su valiosa ayuda. Traducción de Flora Botton-Burlá.

** Institut National d'Études Démographiques (INED), París. 
De hecho, cuando los demógrafos del INED comentan entre ellos la necesidad de liberar la imaginación del investigador para explorar las fronteras de la demografía, al tiempo que se preserva el rigor del análisis formal, el nombre que se les ocurre es con toda naturalidad el de Jean Bourgeois-Pichat. Jacques Vallin me decía recientemente que la audacia de su ilustre predecesor seguía inspirando sus trabajos actuales sobre el porvenir de la esperanza de vida y el porvenir de la longevidad. Henri Leridon, por su parte, siempre ha insistido en su enseñanza en las lecciones que Jean Bourgeois-Pichat nos ha dejado en materia de dinámica de población: el manual de demografía que publicó con Laurent Toulemont en 1996 dedica varias páginas a la famosa demostración publicada en 1970 en la revista Population sobre las consecuencias inesperadas e indeseables de una política que pretendiera anular en unos cuantos decenios la tasa de crecimiento de una población joven, dotada de un fuerte potencial de crecimiento. Como ustedes saben, el ejemplo que se presenta en este artículo de Bourgeois-Pichat y Taleb no es otro que el México de comienzos de los años sesenta, proyectado hasta 2000 y más allá. Y una vez más, el ejemplo mexicano es el elegido en el curso sobre la dinámica de las poblaciones que había impartido Jean Bourgeois-Pichat en el Institut d'Études Politiques de París y que Georges Tapinos publicó a título póstumo.

Personalmente, en mi calidad de sucesor lejano de Jean BourgeoisPichat (dirigió el INED de 1962 a 1971, y otros tres directores me separan ya de él), no tengo más ambición que facilitar el trabajo de los investigadores del INED, procurando que puedan desarrollar conjuntamente las tres cualidades que Bourgeois-Pichat encarnaba tan bien: el rigor del análisis formal, la imaginación científica, y la dimensión internacional. Tengo la tentación de añadir otra cualidad importantísima del oficio de investigador, que él ilustraba mejor que nadie: la capacidad de establecer relaciones de confianza y convivencia con un máximo de colegas y asociados -pero se puede dudar de que el director de un organismo de investigación tenga la posibilidad de influir en las idiosincrasias de los investigadores.

En cuanto a mí, pertenezco a la categoría de los investigadores que, a lo largo de su carrera, han desarrollado las encuestas por muestreo sobre los comportamientos demográficos en una perspectiva cada vez más micro, con la esperanza de que esos nuevos datos, inaccesibles por medio del registro civil o los censos clásicos, puedan alimentar útilmente la investigación demográfica al completar los macrodatos. 


\section{Dos demografías, dos éticas}

En el fondo existen en la actualidad dos grandes vertientes de la investigación demográfica: la macrodemografía y la microdemografía, que corresponden a dos enfoques, dos modos concretos de trabajar.

El primero es encarnado efectivamente por la figura de Jean Bourgeois-Pichat; es una demografía que tiene el privilegio de trabajar desde arriba y desde lejos, a una escala generalmente nacional o planetaria. No pregunta a las personas, no entra en interacción con ellas; recoge los datos administrativos disponibles, critica si es el caso su calidad, analiza las relaciones numéricas entre las magnitudes demográficas y, valiéndose de ese saber, reconstituye o estima una parte de los datos faltantes.

El segundo enfoque consiste en ir a preguntar a las personas, en contar con su capacidad de restituir lo esencial de su trayectoria y, cada vez con mayor frecuencia, en seguirlas de manera repetida o continua, si es necesario durante toda una vida. Los ejemplos son múltiples. Pienso en los observatorios de población que el INED y el IRD mantienen desde hace varias décadas en Senegal y en Malí; en las encuestas longitudinales sobre las intenciones de fecundidad, en la muestra demográfica permanente del INSEE, en las grandes encuestas demográficas europeas de tipo longitudinal que están actualmente en curso sobre las relaciones hombres/mujeres y las relaciones entre generaciones, o bien en el proyecto actual de Henri Leridon en coordinación con el INSERM, sobre los modelos de las cohortes de los niños británicos. Claro está que las encuestas biográficas desarrolladas por Daniel Courgeau y Éva Lelièvre, así como por varios demógrafos del IRD, representan un avance esencial en esa dirección. Evidentemente se podrían citar empresas análogas en México, por ejemplo en los trabajos de observación realizados por El Colegio de la Frontera Norte.

Este enfoque intensivo en las personas, que a veces tiene aspectos de observación antropológica, aparece como cada vez más necesario a medida que los comportamientos individuales escapan a las formas institucionales para refugiarse en los arreglos informales y privados (inicio de unión, separación de hecho, recomposición familiar, residencia múltiple, etc.). También se deriva de la necesidad de pasar de una demografía descriptiva a una demografía explicativa, donde los factores tomados en cuenta ya no sean únicamente demográficos. Jean Bourgeois-Pichat no fue ajeno a esta nueva forma de análisis demográfico puesto que, siguiendo a Sully Ledermann, fue uno de los primeros 
autores que hicieron análisis factoriales en Francia. Como sabemos, se referían a las causas de decesos y se apoyaban en cierta forma en la microencuesta realizada por los médicos en el momento de la defunción. Uno de los resortes del desarrollo de la demografía intensiva fue el deseo de tomar más en cuenta el paso del tiempo al reconstituir las etapas de la biografía individual.

Los dos estilos de demografía están vinculados (pues hace falta diferenciar los niveles y articularlos a la vez), pero insistiré aquí en el hecho de que cada uno de ellos plantea problemas éticos particulares.

El enfoque micro requiere precauciones especiales en la recolección y el procesamiento de datos: confidencialidad, anonimato, transparencia, lealtad, protección de los datos informáticos. No hablaré de ellas aquí; es un tema vasto, cada vez más delicado a medida que las encuestas penetran en las intimidades de las personas y prolongan las observaciones.

El enfoque macrodemográfico, por su parte, da fácilmente a sus adeptos la impresión de ser perfectamente inofensivo, puesto que los datos manipulados no permiten tomar decisiones de carácter individual: no toca a las personas particulares sino sólo a poblaciones anónimas; no se interesa en el tríptico de la vida, el amor y la muerte, sino que se conforma con estudiar prosaicamente los nacimientos, las uniones, los decesos. La macrodemografía no es sentimental ni patética. Cuando estudia la mortalidad infantil no lo hace para llorar por la suerte de los recién nacidos. Mantiene frente a las personas una distancia tal que no puede perjudicar los intereses de nadie. Más aún, la macrodemografía coloca al investigador en una posición de "espectador imparcial" que reviste un valor ético en sí.

La macrodemografía se parece en cierto modo al ejercicio espiritual del sabio de la antigüedad, descrito por Cicerón o Marco Aurelio: imagina que te alejas del mundo, que se reduce a una pequeña esfera, y comprenderás que el caos de las pasiones humanas está ordenado, se reduce a las leyes de la guerra y del mercado, a la sucesión de los nacimientos, las uniones y los decesos, a la rotación de las generaciones. Varias sentencias estoicas que recuerdan este trabajo de distancia y de reducción muestran una visión predemográfica del mundo: la diversidad de los seres humanos deja su lugar a poblaciones que se renuevan. Y el sabio o el erudito desinteresado no es sino el hombre que asiste al espectáculo de todas las transacciones humanas sin participar jamás en ellas. Los historiadores de las ciencias consideran que la construcción 
de este punto de vista imparcial y universalista, muy apreciado por los estoicos, es un momento capital en el surgimiento de la actitud científica (o, como se dijo durante mucho tiempo, de la actitud contemplativa) en Occidente.

Las proyecciones demográficas son un componente muy importante del enfoque demográfico distanciado. El demógrafo no sólo es capaz de ver desde lejos a las poblaciones enteras; ve lejos, y a veces muy lejos. A diferencia de los economistas, que tienen grandes dificultades para vislumbrar cómo será la coyuntura económica dentro de seis meses, los demógrafos cuentan con los medios necesarios para ver en el horizonte de una o dos generaciones, gracias a toda la inercia acumulada de las pirámides de edad. Eso amplía considerablemente el alcance del cálculo de consecuencias que preconiza la moral utilitarista. La demografía alcanza de entrada en este punto una dimensión política y ética.

Si los demógrafos que trabajan desde cerca tienen sus problemas éticos, los demógrafos que trabajan desde lejos tienen los suyos propios.

¿De qué problemas se trata? Volvamos a Jean Bourgeois-Pichat. En su famoso artículo de 1988 sobre el peligro de extinción de la población mundial, se encuentra una breve sección intitulada "La transición industrial y los derechos humanos". ${ }^{1}$ Bourgeois-Pichat explica que la revolución industrial no sólo multiplicó prodigiosamente el consumo de energía y la productividad del trabajo agrícola, dejando a los hombres disponibles para la industrialización; fue acompañada por una "transición de los derechos humanos" cuyas consecuencias son virtualmente considerables, puesto que pone en tela de juicio nada menos que la supervivencia de la humanidad: "Al plantear el principio según el cual todo ser humano está libre de dirigir su destino, aparece el peligro de ver desaparecer la especie. Con la ayuda del progreso técnico, se vuelve posible elegir el tamaño de la descendencia y, si el ser humano está libre, puede decidir no sobrevivir". ${ }^{2}$

La invención de los métodos modernos de anticoncepción no hace sino prolongar un fenómeno que se remonta a la revolución industrial: la libertad de elección se combinó con el progreso técnico para permitir al ser humano reducir su descendencia. La novedad de los años sesenta y setenta del siglo XX es haber incrementado de manera formida-

${ }^{1}$ Jean Bourgeois-Pichat (1988), “Due XXe au XXIe siècle: l'Europe et sa population après l'an 2000”, Population, núm. 1, enero-febrero, p. 31.

${ }^{2}$ Ibid., p. 32. 
ble la eficacia de las técnicas anticonceptivas. Alemania se precipitó en la brecha desde mediados de los años setenta, con una tasa de fecundidad de 1.2 niños por mujer y por consiguiente una tasa bruta de reproducción ligeramente inferior a 0.6 , y su comportamiento prácticamente no ha variado desde entonces. Si los países industriales adoptan a su vez ese comportamiento y lo mantienen de modo duradero, se extinguirán inevitablemente en el horizonte de 2250 y si el resto del mundo hace lo mismo, la especie humana desaparecerá hacia 2400.

Se notará que la prosa del demógrafo sigue siendo de una gran sobriedad. Ni sombra de un sentimiento de indignación, ninguna pasión. El escenario catastrófico se desarrolla de manera imperturbable. Es toda la fuerza del estilo de Bourgeois-Pichat: sustituir las vociferaciones de Casandra o las lamentaciones de Jeremías por la simple enunciación de la estadística. No por ello dejan de existir nuestras angustias, sino que adquieren mayor fuerza al revestirse así con las apariencias de la objetividad.

Es interesante comparar la actitud de Jean Bourgeois-Pichat con las de dos empresas muy diferentes: las profecías apocalípticas de un entusiasta del natalismo, el historiador francés Pierre Chaunu, por una parte, y por la otra, las proyecciones recientes de la ONU.

Chaunu pronunció recientemente, frente a una asociación suiza provida, una conferencia intitulada "Perspectives et projections" (Perspectivas y proyecciones) en el estilo que bien le conocemos, lírico e inspirado, salpicado de referencias históricas (el texto se encuentra fácilmente en internet). Cita el artículo de Bourgeois-Pichat, subraya de paso que éste debería haberlo citado puesto que él mismo había anunciado por lo menos diez años antes la mala nueva de la implosión demográfica de Occidente. Corremos hacia la catástrofe, exclama Chaunu, la humanidad europea se está suicidando, las fuerzas de la muerte van a ganar la batalla. Y señala al enemigo: el egoísmo y el hedonismo, la descristianización, la anticoncepción libre, la píldora del día siguiente, la homosexualidad, etcétera.

A los futuros historiadores de la demografía tocará saldar la cuestión de saber si el pesimismo de Bourgeois-Pichat abreva en las mismas fuentes ideológicas que el de Chaunu. Personalmente no lo creo: el pensamiento de Chaunu descansa en los a prioriabsolutistas provenientes de su creencia en el valor sagrado de la vida, creencia alimentada por una fe religiosa respetable, pero que evidentemente no puede pretender tener un fundamento científico porque se presenta como una verdad revelada propiamente indiscutible. Éste es todo el proble- 
ma de las éticas provida que invocan una ley natural o una ley divina: se sustraen por construcción a la discusión libre y al debate democrático. Si bien se puede admitir que de gustibus non est disputandum, en cambio, como lo recordaba Albert Hirschmann, de valoribus disputandum est. Por ello es que una sociedad tolerante debe tolerar la expresión de éticas intolerantes con la condición de cuidar que nunca puedan dominar y ahogar el pluralismo. Tales enfoques son, en todos los casos, radicalmente incompatibles con la ética de la investigación científica. Desconozco las opiniones personales de Jean Bourgeois-Pichat en materia de aborto y de anticoncepción y, en forma más general, su apreciación de las cuestiones de bioética. Pero no necesito conocerlas pues me basta con constatar que tenía una opinión demasiado elevada de la independencia del investigador y de la necesidad de una libre discusión científica como para aceptar que sus opiniones personales interfiriesen con su trabajo científico.

El enfoque de Bourgeois-Pichat difiere del de Chaunu por lo menos en tres grandes rasgos.

En primer lugar, no proyecta sólo la desaparición de las sociedades industriales sino también la de los países en desarrollo, mientras que la preocupación central de Chaunu es ante todo la desaparición del mundo cristiano en favor de las otras civilizaciones. Cierto es que Bourgeois-Pichat propone una división aproximada de la población mundial en "grandes corrientes espirituales": la cristiandad, China, el Islam y el resto del mundo, para concluir que al ritmo actual, la cristiandad está destinada a perder terreno en favor del Islam, especialmente alrededor de la cuenca mediterránea -un tema que se encuentra también en los escritos de Paul Demeny, en una entrega reciente de la Population and Development Review-. La conclusión de BourgeoisPichat, que se refiere al horizonte de 2100, merece ser citada en el contexto de esa conferencia: "La tradición cristiana 'salva la casa", explica, pero únicamente "gracias a América Latina". Notemos de paso que eso era antes del descubrimiento del prodigioso retroceso de la fecundidad en los países musulmanes. ${ }^{3}$ Pero recordemos sobre todo

${ }^{3}$ Irán, para tomar el ejemplo de una república islámica inflexible, pasó en veinte años de siete niños por mujer a sólo dos, al igual que los países del Magreb; Yemen, que para Paul Demeny es el mismo tipo de país musulmán de fuerte crecimiento, en realidad está bien entrado en su transición demográfica: ya no tiene siete niños por mujer, según las últimas encuestas realizadas por Youssef Courbage, sino de cuatro a cinco. A pesar de los efectos a largo plazo del potencial de crecimiento, la proyección de las distintas "regiones espirituales" del mundo sin duda arrojaría hoy un resultado sensiblemente diferente del que Bourgeois-Pichat pudo calcular hace quince años. 
que Bourgeois-Pichat, lejos de ver en el Islam a un enemigo diabólico que la cristiandad debería contener, concluye en la "necesidad de una colaboración y, en suma, de una reconciliación entre las dos corrientes espirituales". ${ }^{4}$

La segunda característica del enfoque de Bourgeois-Pichat, que lo distingue aún mejor del de Chaunu, es que no presenta las proyecciones demográficas como una profecía inexorable sino como un escenario entre otros sobre los que se debe meditar: esto es lo que pasará si la humanidad sigue el camino abierto por Alemania en materia de reproducción, es decir el camino de una elección individual libre que permanece indiferente a las consecuencias para la colectividad. Aquí podríamos recordar el título de otro artículo de Bourgeois-Pichat: "Bien des choses peuvent se passer en deux cents ans" (Muchas cosas pueden pasar en doscientos años). Nos equivocaríamos, sin embargo, si redujéramos el juego de sus proyecciones a un simple ejercicio escolar; el autor le confería manifiestamente un sentido más profundo: el de un ejercicio socialmente útil que pone a la imaginación al servicio de la acción (o de la reacción). El demógrafo, por esta vía, ejerce un derecho de vigilancia y un derecho de alerta. Nos sugiere, sin elevar la voz, que toda acción sobre la reproducción humana tiene consecuencias que se deben examinar.

Tercera característica: el pesimismo de Bourgeois-Pichat respecto a la capacidad de la humanidad de renunciar a su facultad de libre elección en materia de reproducción, sin considerar las obligaciones del reemplazo, es igualado por su confianza en las posibilidades de reaccionar en un registro completamente diferente, el de un progreso técnico que permitiría abrir los cerrojos biológicos: el límite extremo de la vida humana por un lado, el límite extremo de la vida fecunda por el otro. Un dominio incrementado del proceso de senectud podría hacer pasar la esperanza de vida de la población mundial a 100 años hacia 2050, incluso a 140 años de vida en buena salud, lo que tendría el mérito de retrasar un poco la fecha de la desaparición de la humanidad. Más aún, la duración de la vida fecunda podría alargarse considerablemente, con una menopausia llevada a los 100 años, de tal manera que las mujeres podrían acumular dos uniones en el transcurso de su vida y duplicar su fecundidad para alcanzar el umbral de reemplazo.

Hagamos saltar el cerrojo de la menopausia y la especie estará salvada: esta pirueta final está en el estilo del hombre; da una visión del

${ }^{4}$ Bourgeois-Pichat, op. cit., p. 23. 
porvenir profundamente ambivalente, en la que se mezclan indisolublemente la angustia y el sentido del humor, el espectro de la decadencia colectiva y la esperanza de que la humanidad lleva varios trucos en su alforja y de que podría rebotar, llegado el momento, cambiando radicalmente la situación biológica. En suma, el porvenir se va a jugar en una curiosa carrera de velocidad entre comportamientos individuales irresponsables e imposibles de modificar, por una parte, e innovaciones biotecnológicas que todo el mundo podrá aprovechar, por la otra. Si la revolución biotecnológica llega a tiempo, sus efectos positivos podrán compensar los efectos negativos de los comportamientos.

A decir verdad, tal escenario no es muy tranquilizador. Sugiere que el único remedio para la locura de los seres humanos es el recurrir a la invención de un sabio loco, como si la ciencia ficción fuera el único medio de alcanzar a la demografía ficción. ¿No sería más razonable imaginar que una política demográfica bien concebida pudiera alcanzar la meta del reemplazo de las generaciones sin pasar por tales extremos? Pero Bourgeois-Pichat no parece creer en ella, si consideramos su alusión a las hipótesis de la ONU: la idea de que después de cierto tiempo por debajo del umbral de reemplazo, los países industrializados acabarán por volver al equilibrio al recuperar el nivel de fecundidad necesario para el reemplazo, equivale a imaginar, según él, que una parte de las parejas se volverán conscientes del peligro de desaparición de su país y aumentarán su fecundidad "por espíritu cívico". Asegura que la hipótesis no tiene nada de absurdo, pero su presentación irónica basta para mostrar que prácticamente no cree en ella. En efecto, sería necesario (pero aquí el razonamiento del autor es bastante elíptico y debe ser reconstruido a partir de fragmentos dispersos) que las parejas poblacionistas fueran suficientemente numerosas para contrarrestar las tendencias maltusianas de los defensores de los derechos humanos, que hoy en día ocupan una posición hegemónica. Esta lucha ideológica o ética, como se quiera, sería más incierta, en suma, que la lucha tecnológica.

\section{Las proyecciones de la $\mathrm{ONU}$}

La ONU publicó recientemente proyecciones de población a escala mundial y por países que llegan hasta el año 2300.

$\mathrm{Al}$ proponer una variedad de escenarios sobre la evolución demográfica de los tres próximos siglos, la División de Población de las 
Naciones Unidas tomó una iniciativa valerosa que merece una felicitación. En relación con las proyecciones anteriores, innova al trabajar a la escala de los países y ya no sólo de las regiones del mundo. Pero, sobre todo, hace saltar tres cerrojos: el horizonte se desplaza de 2150 a 2300, la esperanza de vida al nacer ya no está limitada a 85 años sino que rebasa los 100 años en varios países, y se admite ahora que la fecundidad pase cerca de un siglo por debajo del umbral de reemplazo antes de alcanzar el estado estacionario.

Con este modelo, la humanidad salta al porvenir a la manera de un buzo que aguanta el aliento un largo rato antes de volver a la superficie. Pero el final de la historia sigue siendo el happy end al que nos habían acostumbrado los demógrafos de la ONU: el objetivo sigue siendo el retorno al equilibrio demográfico, definido por el reemplazo estricto de las generaciones. La concesión que se hace al esquema de la "segunda transición demográfica" no impide que la teoría inicial de la transición demográfica continúe orientando el trabajo de proyección. Para quien quiera presentar los trabajos de la División de Población al público general (lo cual forma parte de las tareas que tocan a los investigadores de un instituto nacional como el INED), se impone un doble esfuerzo pedagógico. Hay que recordar que se trata de proyecciones orientadas hacia un blanco y explicar después la elección del blanco principal. Para hablar claro, el punto de llegada, lejos de ser producto de la proyección, como espera el profano, está fijado de antemano. Se podría concluir que el poder de predicción de la proyección es nulo por construcción. Pero se ve, en un segundo tiempo, que no por ello deja de tener un valor considerable para la acción, y más aún, que representa la única elección realista -con la condición de no ver en ella el producto de un estado de cosas natural sino una realidad viable y aceptable, construida social y políticamente.

Las críticas formuladas por la corriente natalista en contra de las proyecciones de la ONU son antiguas. Los defensores de esta corriente consideran que el retorno inexorable al equilibrio es un dogma que nada justifica (Dupâquier, 1999). Rechazan la noción de "transición demográfica", porque el postulado de un retorno espontáneo al equilibrio tendría como efecto -si no es que como meta- la desmovilización de las opiniones públicas y de los que toman las decisiones políticas. Prefieren la idea de "revolución demográfica", descrita y deplorada a la vez por Alfred Landry ya desde 1934. Según esta teoría, el aumento del individualismo y el alza del costo de los niños harán hundirse inexorablemente a las sociedades ricas por debajo del umbral de re- 
producción, con la consiguiente despoblación. Esta catástrofe anunciada es la que los demógrafos de la ONU, demasiado sensibles a la ideología maltusiana, se negarían a mirar de frente. La posición de Bourgeois-Pichat representa una versión moderada de este tipo de posición -moderada en la forma pero radical en cuanto a los cálculos presentados.

Otro punto de vista, fundado en análisis profundos del trabajo de la ONU, es el formulado por Graziella Caselli y Jacques Vallin, coautores junto con Guillaume Wunsch del gran tratado de demografía en ocho volúmenes que el INED publica en la actualidad. ${ }^{5}$ Empiezan felicitando a la División de Población por haber logrado, desde 1958, anticipar la cifra de los 6 mil millones de terrícolas que se alcanzó en 2000, con márgenes de error más reducidos en cada nueva proyección. Para ellos, este éxito notable tiene varias causas: el método de proyección orientado hacia un blanco permite, mejor que la extrapolación matemática, tomar en cuenta con flexibilidad una variedad de escenarios cuyo carácter más o menos verosímil se puede juzgar posteriormente; el método de los componentes limita los errores al imponer restricciones contables; las proyecciones efectuadas desde 1958 sobre el horizonte de 2000 fueron de corto alcance y sobre todo, era posible prever razonablemente la evolución de la población de los países en desarrollo al insertarla dentro del esquema de la transición demográfica. En cambio, cuando se trata de los países desarrollados, Caselli y Vallin recuerdan que las once proyecciones publicadas por la ONU entre 1958 y 1993 no alcanzaron su objetivo: la cantidad finalmente alcanzada en 2000 (menos de 1.2 mil millones) se encontró al fin de cuentas al exterior de los márgenes de error anunciados, por abajo de la variante baja. Para alcanzar tardíamente la evolución efectiva de los países desarrollados fue necesario revisar a la baja las hipótesis iniciales. Si la evolución demográfica de Europa escapó tanto tiempo a las previsiones fue, como ahora sabemos, porque la caída duradera de la fecundidad europea por debajo del umbral de reemplazo invalidó el modelo canónico de la transición demográfica. Precisamente de esta comprobación surgió la idea de una "segunda transición" de la fecundidad, enunciada por Van de Kaa y Lesthaeghe. Pero la ONU tuvo suerte: el peso de la sobrepoblación europea era demasiado bajo para que su sobreestimación se reflejara en la calidad global de las proyecciones mundiales. Ahora bien, subrayan Caselli y Vallin, ya no ocurrirá lo mismo en el futuro.

${ }^{5}$ Graziella Caselli, Jacques Vallin y Guillaume Wunsch (2004), Démographie, analyse et synthèse, París, Institut National d'Etudes Dempographiques (INED). 
Cuando la transición demográfica haya agotado la mayoría de su efectos (sólo el África subsahariana se encuentra todavía en el comienzo del proceso), la incertidumbre sobre el porvenir ya no estará confinada a los países desarrollados, sino que se generalizará a todo el planeta, y ello aún más cuanto que la proyección se fijará en un horizonte más lejano. En vez de un retorno al equilibrio, se podrían descubrir recorridos inéditos y llenos de repercusiones. ¿Quién podrá decir, por ejemplo, si India y China se instalarán o no en forma duradera por debajo del umbral de reemplazo?

A esto se añaden otros factores de incertidumbre que limitan la capacidad de predicción de las proyecciones. De la misma manera en que los hechos se encargaron de hundir el piso de la fecundidad, existe un fuerte riesgo de que rompan el techo de la esperanza de vida: ¿hasta dónde se elevará? Carecemos de una teoría para enmarcar la evolución futura de la fecundidad, y también carecemos de una teoría equivalente para la mortalidad. El principio de convergencia-estabilización supone que la fecundidad se mantendrá alrededor de 2.1 niños por mujer y que la esperanza de vida se estabilizará en cualquier nivel que sea. Si continúa su progresión al ritmo de las últimas décadas, que ya habían rebasado las previsiones más optimistas (con la dramática excepción de los países afectados por el sida), contribuirá a desestabilizar el crecimiento elevando cada vez más la pirámide de edades.

En cuanto a las migraciones internacionales, su flujo y su dirección siguen siendo grandes incógnitas, de tan volátil que es el fenómeno. En el transcurso de los tres siglos anteriores los flujos cambiaron profundamente de naturaleza. Las grandes migraciones de población hacia el Nuevo Mundo -54 millones de 1815 a 1930, según Dudley y Baines- no tienen equivalente hoy en día. Los flujos también tuvieron inversiones espectaculares (Europa del sur se ha convertido en receptora de mano de obra después de haber sido emisora durante largo tiempo). En tres siglos todo puede ocurrir en el campo de las migraciones, incluso (por incongruente que eso pueda parecer en la actualidad) importantes movimientos migratorios del norte hacia el sur, en sentido inverso de los flujos actuales, y vinculados con nuevas formas de codesarrollo. Si el sur se desarrolla alrededor de algunos países o de algunas aglomeraciones que funcionen a manera de guía, puede polarizar una inmigración venida del norte que traiga transferencias de tecnología y de personas con la formación necesaria. Esta hipótesis va de acuerdo con el hecho de que las migraciones siguen siendo controladas por los países en posición dominante, cualquiera que sea el 
sentido de los flujos. Como lo ha recordado Vallin, Europa pudo exportar libremente hacia los países de ultramar sus excedentes de población en los siglos pasados, no vacilando en emplear todos los medios de coerción de que disponía. Una vez acabada su transición, se abrevó en los excedentes de mano de obra del Tercer Mundo antes de volver a cerrar sus puertas, mal que bien, cuando llegó la crisis. ¿Es absurdo imaginar que los países desarrollados, sin renunciar a su poder de control de los flujos migratorios, lleguen a la conclusión de que su interés bien entendido pasa por un codesarrollo que implique una circulación migratoria más intensa con los países en desarrollo? ${ }^{6}$

Caselli y Vallin no entran en este tipo de especulación, que es propio de nosotros. Pero su conclusión es clara: el porvenir de los tres componentes de la evolución demográfica -fecundidad, mortalidad, migraciones- sigue más inseguro que nunca. Ya no sabemos a qué teoría apelar para conjeturar el sentido de sus evoluciones respectivas. Esas incertidumbres, mantenidas a lo largo de tres siglos, no permiten dar a las proyecciones el menor valor de previsión o de "previdencia".

En estas condiciones, ¿no habría que optar por la técnica de las proyecciones probabilísticas, como nos invitan a hacerlo demógrafos como Wolfgang Lutz o Nico Keilman? El problema es que se vuelve imposible, considerando el horizonte de tres siglos, dar un sentido al intervalo de confianza que debe acompañar a cada proyección. Si aprendemos que hay un $95 \%$ de posibilidades de que, de aquí a trescientos años, la población mundial sea de entre 2.5 y 36 mil millones

${ }^{6}$ Durante las consultas de expertos organizadas por la División de Población, se presentó la idea de estimar el volumen de las migraciones internacionales considerando que serían directamente proporcionales a la población de los países involucrados e inversamente proporcionales a la distancia. Se trata de un modelo gravitacional presentado desde 1885 por Ravenstein. Su utilidad principal es fijar un margen de error máximo de los flujos migratorios permitidos por la dimensión de las poblaciones involucradas. Más allá de ese papel de contención aritmética, sabemos que tales modelos no tienen ningún poder de predicción. Si las migraciones obedecieran mecánicamente a las leyes de gravitación (de las "altas presiones" demográficas hacia las "bajas presiones" o de las áreas pobres hacia las áreas ricas), la inmensa mayoría de los países en desarrollo habría migrado desde hace mucho y las migraciones mexicanas a Estados Unidos, para no tomar más que ese ejemplo, serían mucho más importantes de lo que son. Ahora bien, la fracción de la población mundial actualmente instalada en el extranjero no rebasa 3\%. Los flujos migratorios no se explican únicamente por factores demográficos. Las guerras, los conflictos, las persecuciones explican buena parte de ellos. El carácter desregulado del mercado de trabajo (mucho más acusado en Estados Unidos o en Europa del sur que en Europa del norte, por ejemplo) es un poderoso factor de atracción de migrantes irregulares. Y eso sin contar el control de las fronteras nacionales o comunitarias, que es más eficaz de lo que se dice (el obligar a los migrantes a hacer tres tentativas de entrada en vez de una tiene el claro efecto de frenar los flujos y de disminuir las cantidades). 
de habitantes (que son los márgenes anunciados por la ONU para 2300), no habremos ganado mucho. ¿No sería más sabio reconocer que nuestro saber a tan largo plazo se limita a saber que no sabemos nada?

El escepticismo sobre el interés de las proyecciones aumenta cuando conocemos las rupturas y las catástrofes que sufrió el siglo Xx. ¿Podremos evitar en el porvenir los conflictos, las guerras, los genocidios, con sus efectos directos e indirectos (muertes prematuras, nacimientos anulados, poblaciones desplazadas)? La densificación urbana y la aceleración de los intercambios entre continentes, ¿no van a favorecer nuevas epidemias mundiales, análogas al sida o a la "gripe española”? ¿Y que será de las catástrofes tecnológicas (accidentes nucleares, por ejemplo), climáticas (del tipo de la canícula de agosto de 2003 en Francia) o cósmicas (caída de asteroides)? Esas rupturas, imprevisibles a corto y mediano plazo, lo son aún más a largo plazo. Se puede pensar que invalidan de antemano la hipótesis de una estabilización plurisecular de los comportamientos.

¿Qué valor atribuir a esas críticas o a esos interrogantes?

Hay que disipar un primer error. El colocar el escenario central de las proyecciones en la misma línea del umbral de reemplazo no carece de todo valor normativo en sí. Es en primer lugar un modelo de referencia que permite medir las desviaciones entre la realidad y el modelo; modelo del que, por su parte, la teoría de la "revolución demográfica" no puede prescindir (cuando Adolphe Landry propuso en los años 1930 que se luchara contra la despoblación, preconizó tomar como meta un "óptimo de población" capaz de restaurar el reemplazo de las generaciones). Nada indica que el escenario catastrófico de la "revolución demográfica" y sus adaptaciones recientes den un marco provisional mejor que el esquema clásico de la transición. Sería paradójico elogiar su capacidad de prever la caída actual de la fecundidad europea, cuando no permitió anticipar el baby boom de los años 19401960, que sin embargo era mucho más cercano.

El escenario central de una proyección orientada a un blanco puede ser fijado de antemano por quien la hace, pero no por ello está "visto de entrada". Lejos de presuponer el statu quo, el escenario central supone para mantenerse importantes cambios de comportamiento, vinculados con una sólida capacidad colectiva de acción y de reacción. La División de Población efectivamente consideró el mantenimiento del statu quo, pero para ello fabricó otro escenario que consiste en mantener durante tres siglos las tasas de fecundidad actuales. Este escenario de "fecundidad constante", construido con fines pedagógicos, 
es espectacular; de él resulta una derivada exponencial de las tasas que demuestra por el absurdo que es imposible congelar en forma duradera las desviaciones de comportamiento que separan actualmente a las regiones del mundo.

Esta revelación no tiene nada de nuevo: es una verdad básica que una tasa de crecimiento se vuelve exponencial si se prorroga de idéntica manera en un largo periodo. Pero vale la pena ilustrarlo concretamente. Bajo la hipótesis de la fecundidad constante, Francia metropolitana ya sólo contaría con 21 millones de habitantes en 2300, mientras que sus departamentos y territorios de ultramar (Martinica, Guadalupe, Guyana, Reunión, Nueva Caledonia, Mayotte) tendrían un total de... ¡234! La relación numérica entre la metrópolis y los territorios de ultramar sencillamente se invertiría. Más generalmente, si el nivel de fecundidad debiera quedar petrificado durante tres siglos, los países que actualmente se sitúan debajo del nivel de reemplazo verían su población dividirse entre ocho, mientras que los que rebasan el umbral de reemplazo, aunque sólo fuera por 0.25 niño, verían crecer su población de manera exponencial, con resultados extravagantes.

A la escala de los continentes, las desviaciones vuelan hacia el infinito si se congelan por tres siglos los niveles actuales de fecundidad: África alcanzaría... 115 billones (115 000 milliards) de habitantes y concentraría $86 \%$ de la población mundial en vez del 13\% actual, mientras que Europa o América del Norte estarían cercanas a la extinción: 90 millones de habitantes en vez de 730, o sea una fracción de la población mundial cercana a cero. En cuanto se intenta petrificarlo, el presente se vuelve irreal e insostenible, porque la coyuntura del momento supone velocidades de evolución instantáneas muy desiguales que no tienen ninguna razón de perdurar. Lo que separa a los países y los continentes en un momento dado son desfases cronológicos en los recorridos y en los ritmos de movimiento, de ninguna manera diferencias de naturaleza irreductibles, como a veces se imagina.

Pero quizás lo más importante sea lo siguiente: la hipótesis de alta fecundidad considerada por los demógrafos de la ONU tampoco es realista, aunque se conforma con añadir al nivel de fecundidad del escenario central unos cuantos decimales de niño. Con una fecundidad que alcanza, según los periodos, entre 2.15 y 2.35 niños por mujer, lo que apenas representa medio niño más que los 1.9 actuales, llevaría a la Francia metropolitana a un total de 248 millones de habitantes en $2300 \ldots$ Tan cierto es que una leve desviación en un factor de crecimiento puede crecer de manera exponencial. En cuanto a la hipótesis 
de baja fecundidad, es igualmente inverosímil. Supondría para Francia un estancamiento de la fecundidad durante casi un siglo en alrededor de 1.35 niños, cuyo saldo sería una pérdida de población de casi dos tercios, que ningún gobierno puede aceptar. Que se nos perdonen esas referencias francocéntricas: los expertos de cualquier otro país seguramente tendrían una reacción análoga.

En suma, en este ejercicio basta con disparar flechas demasiado pesadas o demasiado ligeras para que se pierdan en la lejanía. Por más que las variantes de alta y de baja fecundidad que rodean al escenario central se conformen con añadir o con sustraer una fracción de niño a la hipótesis central, acaban por acumular al filo de las décadas desviaciones cada vez más irreales, cuya consecuencia es, por repercusión, que el escenario central sea la única proyección viable. El escenario del retorno al equilibrio no es realista por naturaleza; su realismo resulta de la comparación con los escenarios alternativos.

¿Significa esto que la humanidad, a menos que haya una catástrofe, está destinada a seguir un camino ya trazado? Es efectivamente una especie de determinismo demográfico lo que la División de Población nos invita a postular para el largo plazo, con la diferencia de que es un determinismo indeterminado. Estamos seguros de que la humanidad no puede permitirse perpetuar excedentes o déficits duraderos en materia de crecimiento, so pena de desestabilizarse. Pero no podemos decir por cuáles rodeos y variaciones de ritmo logrará evitarlos, sabiendo que la humanidad se reparte en una gran cantidad de países. La imagen del ciclista o del conductor que conserva su trayectoria con la condición de corregir las desviaciones de equilibrio representaría mal la situación. Las poblaciones que comparten el planeta más bien se parecen a los carritos de un tiovivo unidos a su riel por una barra móvil cuya función es aumentar las sensaciones fuertes. Podrán bambolearse alrededor de su trayectoria, disminuir o acelerar su velocidad al ritmo de las turbulencias, hasta dar por momentos la impresión de un mal funcionamiento, de tardar mucho tiempo para amortizar las oscilaciones, pero no por ello dejarán de ser atraídos por una fuerza de retroceso que los regresará siempre al eje central y, sea como sea, los hará proseguir su trayectoria en el sentido adecuado, sin salir de la ruta... Es un modelo de viabilidad, con todas sus limitaciones, pero de viabilidad turbulenta, incluso caótica.

$¿$ Hace falta recordar que las proyecciones de la ONU no privilegian ninguna interpretación normativa? Un adepto de Malthus puede inquietarse al ver que ciertas tasas de fecundidad saltan a alturas vertigi- 
nosas, mientras que un natalista se indignará al ver que otras se hunden. Pero, volens nolens, ninguno de los dos puede liberarse de la idea reguladora de un equilibrio que se debe mantener entre las diversas regiones del mundo y en el seno de cada sociedad: el mismo enfoque natalista, en su preocupación por compensar el envejecimiento, difícilmente puede preconizar un nivel de fecundidad que rebase duraderamente el umbral de reemplazo. Por más que se cite ritualmente la expresión de Alfred Sauvy, "crecer o envejecer", no permite ignorar que un crecimiento eternamente renovado es imposible de sostener, aun si es moderado. En cuanto al hombre con sentido común, ni natalista ni maltusiano, sino simplemente realista, evaluará de manera rigurosamente simétrica las consecuencias no realistas a largo plazo de las variantes altas o bajas de las proyecciones demográficas. Si la humanidad es capaz de reaccionar a tiempo frente a esas desviaciones a favor de una solución viable a largo plazo (y en trescientos años tendrá tiempo de reaccionar varias veces), preservará todas sus oportunidades de inscribir el porvenir de la población mundial en una zona cercana de la variante central de la proyección. Planteada al comienzo como un simple postulado de conveniencia, la idea de un equilibrio tendencial conquista su legitimidad a la larga, por eliminación de los demás escenarios, y así es como se enriquece en contenido y acaba por imponerse como el único objetivo de referencia razonable.

Volvamos a Bourgeois-Pichat.

$¿$ Son poco razonables las ideas que se le ocurren para bloquear el envejecimiento y retrasar la menopausia? ¿Se conformó con invocar una esperanza loca sin creer él mismo en ella? Todo indica lo contrario. Leyendo atentamente su artículo, se comprende que su visión plurisecular del porvenir se nutre de una visión histórica de muy larga duración. Varias veces en su historia la humanidad ya dio pruebas de que no era pasiva sino que había logrado comprometerse en revoluciones que trastornaron la distribución demográfica: almacenamiento de bienes alimentarios, paso a una agricultura sedentaria, domesticación de los animales, transición industrial, transición epidemiológica. Uno siente la tentación de agregar a todo esto la revolución científica que permite precisamente recolectar los datos demográficos del mundo entero para hacer el cuadro de datos de la población mundial, instrumento indispensable para la concientización y para tomar decisiones. Los medios de conocimiento y los medios de acción no han dejado de desarrollarse. Pensamos en el proceso visionario de Condorcet en el décimo y último periodo del Tableau des progrès de l'esprit humain. Para 
atreverse a creer, ya desde fines del siglo XVIII, en la capacidad de la humanidad para abolir la mortandad infantil y hacer retroceder los límites de la vida humana hasta un límite indefinido, no bastaba con tener imaginación, había que representarse la historia de la humanidad como una secuencia de rupturas en que la realización de cada etapa condiciona la probabilidad de aparición de la etapa siguiente y da razones adicionales para creer en el progreso. "Mostrar las etapas de lo que hoy nos parece una esperanza quimérica, debe parecernos sucesivamente posible e incluso fácil" (Condorcet, Esquisse d'un tableau historique des progrès de l'esprit humain, Prólogo).

Entendida en este sentido, la idea de progreso no tiene nada de una creencia ingenua en el desarrollo inexorable de un porvenir programado de antemano. Prueba de ello es este pasaje en el que Bourgeois-Pichat, que no suele teorizar, vuelve a un argumento de Roy Walford para explicar que una mutación decisiva en el progreso de los conocimientos tiene tantas más posibilidades de ocurrir cuanto que nos encontramos frente a modelos explicativos parciales que sólo necesitan unificarse para colmar sus respectivas lagunas. ${ }^{7}$

Pero ¿cómo tener efecto en el comportamiento humano? ¿Y de qué medios de acción lícitos disponemos?

Los demógrafos, decía Bourgeois-Pichat, nunca pierden de vista el largo plazo, mientras que los "tomadores de decisiones", entre los que incluía los cortes de edad bien establecidos de los que tienen entre 30 y 59 años, viven atados al corto plazo y no se interesan en el porvenir. ${ }^{8}$ La única manera de salvar la situación sería entonces insuflar en el cerebro de los microagentes la conciencia de las macrorrealidades percibidas por el demógrafo, ampliar el horizonte de sus estrategias personales al de las generaciones futuras. La evocación del "civismo" tiene esta función. Esto plantea un problema inseparablemente político y ético. ¿Se le puede pedir al microagente que "piense macro", esperando que el paso de un nivel a otro se obtenga apelando a la reacción cívica? El cortocircuito de los niveles micro y macro tiene todas las características de un paralogismo que ya no puede ser tolerado por las teoría modernas de la acción y de los efectos de agregación.

Es el problema de las políticas de control del comportamiento de los automovilistas. Para reducir el número de accidentes de carretera no basta con exponer a cada conductor las macroconsecuencias de su conducta. Es necesario que ese trabajo esté acompañado de acciones

${ }^{7}$ Bourgeois-Pichat, op. cit.., p. 21.

${ }^{8}$ Ibid., p. 15 
simultáneas en las infraestructuras carreteras, el mantenimiento de los vehículos, la vigilancia policíaca, la redacción de los contratos de seguros. La acción moral debe apoyarse en incitaciones físicas (como los "topes" tan frecuentes en México o como la imposición del cinturón de seguridad). El razonamiento ético del Estado combina razonamientos de tipo "utilitarista" y razonamientos de tipo "virtuista" o "perfeccionista". Por un lado, las obligaciones que impone a los individuos son legítimas si tienen como consecuencia mejorar la seguridad de la mayoría. Por otro lado, hay que llevar primero al conductor a respetar las reglas de tránsito por malas razones, como el miedo a las multas o el miedo a perder su descuento en el seguro, para que se acostumbre progresivamente a respetar las reglas por buenas razones, como la preocupación por el otro o el sentido del deber.

Igualmente, una política demográfica no puede reducirse a inculcar principios poblacionistas en el cerebro de los agentes (seguramente existen ejemplos de poblaciones, como la palestina, que utilizan a sabiendas el arma demográfica para afirmar su presencia en un territorio controvertido, pero esos ejemplos son más bien escasos y están vinculados a circunstancias históricas muy precisas). Una política de población tampoco puede limitarse a recordar que los individuos son libres de fijar el número de sus hijos y libres de elegir el momento en que van a tenerlos (como dice la Convención Internacional de Derechos Humanos de Teherán y como aparece en la Ley de Población de México, por ejemplo). Y hay que dar a las parejas los medios necesarios para ejercer esa libertad de modo que su libre elección reproductiva pueda inclinarse igualmente hacia un aumento o hacia una reducción del número de hijos. Desde ese punto de vista, la política demográfica difícilmente se distingue de una política familiar, de una política escolar, de una política de salud (cuestión que el término de salud reproductiva tuvo el mérito de recordar) o de una política de derechos humanos (por ejemplo, al hacer totalmente igualitario el estatuto jurídico de los niños, sin importar que sus padres estuvieran casados o no). También se podría citar la política del hábitat: una alcaldía que trata de transformar la ciudad en un lugar más agradable para la vida de los niños aporta una contribución evidente a la política demográfica. De manera más general, una política de población no puede disociarse de una política social que aligere el costo del niño y facilite la conciliación de la vida familiar y de la vida profesional.

$¿$ ¿Hace falta que los Estados o las colectividades locales se ocupen de las motivaciones que impulsan a los individuos a tener hijos y guar- 
den su ayuda para las mejores motivaciones? En realidad existen mil razones para tener hijos: se puede tener hijos por amor a los niños, por interés, para tener seguridad en la vejez, para que la herencia no salga de la familia, por egoísmo o por altruismo, para romper la soledad, por conformismo, por amor al peligro, amor al riesgo, por deber, por temor al qué dirán, por temor al castigo divino, para dar gusto al cónyuge, para retener al cónyuge, para dar gusto a los propios padres, por voluntad de sobrevivir en otro, para transmitir ciertos valores, y así sucesivamente. Estos motivos son insondables en su mayoría; a menudo son contradictorios y pueden entreverarse en forma inextricable. Ninguna encuesta, por fina que sea, ha logrado jamás identificar el conjunto de esos motivos ni medir la fuerza de cada uno de ellos. Si se considera esta lista, queda claro que el civismo no es más que un motivo entre muchos otros de tener niños: sería vano contar sólo con él para invertir la tendencia demográfica. Por esto es que una política demográfica debe ser necesariamente multiforme si pretende entrar en resonancia con una parte de las motivaciones de la población.

\section{Comentario sobre la propuesta de Birnbacher}

Los estudiosos de la ética suelen debatir sobre la cuestión de saber si el Estado debe adoptar una actitud neutral en relación con las preferencias individuales o una actitud "perfeccionista", incluso "paternalista", buscando favorecer los sistemas de preferencias más útiles para la colectividad.

Las intervenciones de los poderes públicos en materia de población suelen considerarse como pertenecientes al campo de la política más que al de la ética. En efecto, el paso de la política a la ética supone que el punto de vista de los gobernantes ya no ocupe exclusivamente el primer plano y que se dé un lugar prominente al punto de vista del agente moral individual. Para que se despliegue el espacio de la reflexión ética es necesario, por definición, que los sujetos tengan suficiente libertad y facultad de elección. No hay dilemas morales sin posibilidad de elección. La definición misma de lo justo y del bien debe poder ser objeto de discusiones y deliberaciones.

Los especialistas en ética se han ocupado de cuestiones de demografía. Seguiré aquí la reflexión propuesta por Dieter Birnbacher, estudioso de ética alemán autor de varios trabajos sobre la responsabilidad frente a las generaciones futuras, a quien debemos sobre todo el 
artículo "Población: ética de la población y de las generaciones futuras" en el gran diccionario de ética y de filosofía moral dirigido por Monique Canto-Sperber (este diccionario, cuya primera edición es de 1996, se acaba de reeditar por cuarta vez en un formato de bolsillo de precio accesible).

En materia de población, Birnbacher distingue dos tipos de temas: las cuestiones axiológicas, es decir las cuestiones relativas a la dimensión óptima de la población, y las cuestiones normativas, que se refieren a las formas legítimas de dirigir el crecimiento o el decrecimiento demográfico.

Por lo que se refiere a las cuestiones axiológicas, el punto de partida del filósofo alemán es simple. La intuición nos dice que el tamaño de una población (empezando por la población mundial) no debe ser ni demasiado pequeño ni demasiado grande. Si fuera demasiado pequeño pondría en peligro la diversidad mínima necesaria para la supervivencia de la especie humana. Si fuera demasiado grande llevaría a una sobrepoblación que afectaría la calidad mínima de la vida y correría el peligro de agotar los recursos naturales disponibles. Como vemos, son intuiciones bastante someras que merecerían una amplia discusión científica. Birnbacher no va por este camino; parece considerar que esos dos límites constituyen extremos suficientemente alejados entre sí para que una política demográfica aceptable en el plano ético se ubique necesariamente entre los dos. En esta etapa el filósofo se conforma con restituir los elementos que constituyen nuestro sentido común en este campo.

A la idea intuitiva de que se debe evitar tanto lo demasiado como lo demasiado poco, Birnbacher añade lo que presenta como una verdad de experiencia: es mejor que el crecimiento o el retroceso de la población sean progresivos que demasiado bruscos. Las caídas demasiado rápidas afectan los equilibrios entre generaciones (Birnbacher menciona los efectos en los sistemas de jubilación), mientras que las explosiones demográficas afectan el nivel de vida de las poblaciones. Birnbacher no parece conocer el artículo de Bourgeois-Pichat y Taleb sobre la inercia acumulada en una pirámide de edades muy joven que de todos modos hace imposible poner en práctica una política de interrupción demasiado rápida del crecimiento.

¿Cómo fijar el "justo medio" que definiría una evolución óptima de la población entre lo demasiado y lo demasiado poco? Birnbacher explica que la respuesta a esta pregunta supone la resolución previa de un problema ético más fundamental: ¿qué es lo que puede justificar 
que se traiga al mundo una vida adicional? La filosofía moral elaborada desde hace algunos siglos en Occidente se encuentra un poco desarmada para contestar. Vacila en fin de cuentas entre dos grandes familias de justificación ética: el sistema utilitarista, por un lado, y el sistema deontológico de los derechos de la persona, por el otro. Dos sistemas que son a la vez indispensables e inconciliables. Tratemos de ver esto con mayor claridad.

La política demográfica se inscribe más bien a priori en una perspectiva utilitarista, aunque sea de manera implícita. Parte de la idea de que el objetivo por alcanzar, según la expresión de Jeremy Bentham ya anticipada en el siglo XVIII por el teólogo William Paley, es "la mayor felicidad para el mayor número". En esta perspectiva, la acción no tiene valor intrínseco sino que se juzga en función de sus consecuencias: es buena si incrementa la cantidad de felicidad. Así pues, se puede considerar que ciertas acciones tengan efectos negativos a corto plazo o efectos negativos para ciertas personas si éste es el precio que se debe pagar para mejorar la situación de la mayoría. Añadamos que existe una afinidad notable entre el enfoque demográfico y el enfoque utilitarista: ambos aparecieron progresivamente entre fines del siglo XVII y comienzos del XVIII, antes de consolidarse en vísperas de la Revolución Francesa. Y ambos se caracterizan por la reivindicación, revolucionaria en fin de cuentas, de un enfoque imparcial de las vidas humanas, que otorga el mismo peso a cada uno, sin hacer intervenir la mínima consideración de valor jerárquico o religioso: "todo el mundo vale uno y cada uno sólo vale uno". Esta reivindicación de imparcialidad constituye también la posición de principio del cálculo demográfico.

$\mathrm{Si}$ adoptamos la perspectiva utilitarista, es evidente que se vuelve lícito ejercer una coacción en los ciudadanos para lograr objetivos de bienestar económico y social en beneficio de la mayoría. La política del hijo único en China, o la política de esterilización aplicada en un tiempo en India, pueden justificarse por la necesidad de elevar el nivel de vida de la mayoría.

Birnbacher recuerda sin embargo que existen dos variantes del cálculo "felicífico" ideado por Jeremy Bentham y sus sucesores, según se considere la suma de felicidad o la felicidad media.

Una primera variante toma como criterio la suma de bienestar obtenida en una sociedad: el nacimiento de un individuo más es algo bueno porque incrementa la cantidad total de bienestar. Al menos lo es cuando la vida de los recién llegados parece digna de ser vivida, es decir, alcanza un umbral mínimo de bienestar. Es evidente que estos planteamientos 
presentan numerosos problemas. Al interesarse exclusivamente en la suma total de bienestar, se deja de lado la cuestión de la justa distribución del bienestar en el seno de la población. El criterio no establece ninguna diferencia entre más bienestar para los mismos individuos y más individuos que reciben el mismo bienestar. Calidad y cantidad son intercambiables mientras su producto siga siendo idéntico.

La segunda variante se denomina utilitarismo del beneficio medio. Lo que se valora es la elevación del nivel promedio o del nivel medio de bienestar. El nacimiento de más individuos sólo es bueno si su nivel de bienestar es superior al nivel medio. Esta variante no es menos extraña que la primera. El número de hombres se vuelve indiferente. Toda vida adicional es percibida como una degradación de la situación general si está destinada a un bienestar inferior a la media. Así pues, se supone que se puede prejuzgar a priori sobre la trayectoria de una vida en la escala del bienestar y se olvida que la noción misma de promedio implica, por construcción, que una parte considerable de la población se sitúe ya por debajo de la norma (la mitad si se razona en términos de media). ¿Debemos considerar que su vida no merece ser vivida al mismo grado que las demás vidas?

Las soluciones que han propuesto ciertos autores para combinar el utilitarismo de la suma con el utilitarismo del promedio son complejas y poco convincentes. Proponen coeficientes de ponderación arbitraria para limitar el alcance del criterio cuantitativo y aumentar el del criterio cualitativo.

El demógrafo tal vez juzgue que estas discusiones son ingenuas y abstractas. Sería un error pues la demografía misma aborda las cuestiones de arbitraje entre calidad y cantidad cuando pondera las existencias por el número de años vividos, el número de años que quedan por vivir o el número de años en buena salud. Basta, por ejemplo, con ponderar las tasas de mortalidad por el número de años de vida perdidos para que pueda invertirse la apreciación de un problema social. Las personas de edad avanzada se suicidan más que los jóvenes, pero el suicidio de los jóvenes tiene como resultado el sacrificio de un número muy superior de años vividos. Por lo tanto, merece una mayor atención por parte de los poderes públicos. Otro ejemplo: se puede considerar que la enfermedad de Alzheimer presenta un problema de salud pública más grave que el sida, en razón de la gran cantidad de personas a las que alcanza, pero como el sida afecta a personas jóvenes en plena actividad, incluyendo a mujeres todavía fecundas, es posible que el número de años vividos alcanzados por la enfermedad o el número de vidas 
perdidas en la generación siguiente lleven a invertir el diagnóstico e inciten a los poderes públicos a revisar la distribución de los financiamientos a la investigación entre los dos tipos de enfermedad.

Un problema más radical y sin solución es que no existe ninguna respuesta fija al problema de saber si la vida vale la pena de ser vivida. Comparar una vida con el no ser que le antecedió no tiene ninguna utilidad: sufrimos ante la idea de desaparecer algún día, de ninguna manera sufrimos por saber que no éramos nada antes de haber sido concebidos. Se puede pensar que un mundo en el que viven niños está más vivo que un mundo sin niños. Pero este razonamiento vale para los vivos que ya están aquí, no tiene ningún valor para los niños por venir, que no han pedido nada. Por otra parte, todos somos productos de un encuentro que hubiera podido no surgir. Es imposible decir si tenemos más suerte por haber nacido que por no haber nacido, pues la nada no ofrece ninguna base para la comparación. Para los budistas y los filósofos nihilistas estilo Schopenhauer, incluso hubiera sido mejor que el mundo no existiera. $\mathrm{O}$ más sencillamente: podemos sufrir por vivir, nunca sufrimos por estar muertos. Todo esto relativiza considerablemente la idea sencilla desarrollada por el utilitarismo, según la cual cada vida incrementa la cantidad de felicidad en este bajo mundo, con tal de que se pueda vivir con dignidad. El umbral a partir del cual se estima que esta vida merece ser vivida es eminentemente variable según los medios y los sistemas de valores. Prueba de ello es la violencia de la polémica iniciada por las asociaciones de padres de niños discapacitados contra el filósofo Peter Singer cuando fue nombrado titular de la cátedra de ética en Princeton.

Se puede proseguir esta reflexión con base en los análisis de Anne Fagot-Largeault, profesora de bioética en el Collège de France. Si bien es cierto que la mayoría de los seres humanos dan pruebas de un formidable instinto de conservación, que se muestra en especial en la voluntad continua de sostener el progreso médico y de prolongar la vida, voluntad firmemente apoyada por los poderes públicos, también lo es que esta voluntad de vivir no es compartida por todos. Cada año se cuentan en Francia más de doce mil suicidios, sin contar los intentos, diez veces más numerosos, y los múltiples comportamientos suicidas o de riesgo vinculados con el alcoholismo, el tabaquismo, la anorexia, la práctica de deportes extremos, o con la voluntad de escapar al encarnizamiento terapéutico. Desde la antigüedad, los Estados nos explican que es hermoso "morir por la patria" (véase el famoso artículo de Kantorowicz sobre este tema). Y las religiones veneran a sus márti- 
res. La idea básicamente utilitarista de que vale la pena sacrificar la vida por una causa más grande que uno mismo tiene un gran valor en nuestras civilizaciones. Durkheim trató de laicizar este punto de vista al distinguir entre suicidio egoísta y suicidio altruista, pero esta distinción es difícilmente aplicable en el detalle (podemos buscar la muerte para liberar a otros del peso de nuestra vida). Anne Fagot-Largeault recuerda simplemente que las valorizaciones respectivas de la vida y de la muerte presentan históricamente todas las combinaciones. Para unos, la vida es buena y la muerte es buena (hay que morir para que la vida prosiga). Para otros, la vida es buena y la muerte es la que lo echa todo a perder (lo cual justifica prolongar la vida al perseguir en la tierra el sueño de la inmortalidad). Para otros, como Sócrates frente a sus jueces, nadie sabe si vale más vivir o morir. Para los místicos, la vida es un sufrimiento del que la muerte libera. Y así sucesivamente. Así pues, no existen argumentos racionales y consensuales para justificar que una vida vale la pena de ser vivida. Y por consiguiente, no hay argumento para justificar la condena del suicidio: después de haberlo prohibido durante mucho tiempo, las sociedades y las grandes religiones han acabado por admitir que traducía la libre elección del interesado y no merecía ningún castigo póstumo.

Hagamos una transposición de este debate a la temática del "suicidio colectivo" implicado a largo plazo por la persistencia de una demografía por debajo del umbral de reemplazo. La voluntad de supervivencia no tiene más justificación racional cuando se aplica a una sociedad entera que cuando que cuando se aplica a un individuo particular. ¿Acaso el balance de la humanidad permite concluir racionalmente que su desaparición sería más un mal que un bien? Es difícil probarlo. Los seres humanos no están en posición de juzgar al respecto. Si adoptáramos el punto de vista animal, sin hablar del punto de vista de los equilibrios ecológicos del planeta, el juicio sin duda sería negativo. En tales condiciones, ¿tiene sentido alegrarse al ver aumentar una población y lamentarse al verla disminuir? Sólo tiene sentido por comparación. Desde una perspectiva utilitarista, por ejemplo, el suicidio del pobre o del impotente se entiende, el del rico es incomprensible, incluso inconveniente. Parece significar que la búsqueda de la calidad puede hacerse en detrimento de la cantidad, hasta el punto de que la élite que se beneficiaría de ello podría verse reducida a la nada. Lo que puede parecer escandaloso en el caso de la "segunda transición demográfica” que vive actualmente la mayoría de Europa y es inminente en los países en desarrollo, es el hecho de que los países 
donde la calidad de vida parece ser máxima son precisamente aquellos en que la reproducción de las generaciones está más amenazada (Francia constituye por el momento una excepción notable).

Así pues, nos encontramos en pleno nihilismo. Para escapar al nihilismo no hay más solución, en fin de cuentas, que decidir creer que la vida es buena. Sin embargo, "la vida" es una posición que adquiere tanto más valor ético cuanto que se destaca sobre un fondo de nihilismo. Si la voluntad de vivir puede adoptar un valor ético no es porque esta voluntad sea dictada desde arriba por una voluntad divina o una ley de la naturaleza, sino porque la voluntad de vivir resulta de una elección que nos corresponde. Reconocemos ahora, y cada vez más, que la facultad de destruirse o de renunciar a la vida es un derecho inalienable de la persona humana. El razonamiento es igual para la vida que damos: damos la vida al renunciar a dejar de darla, es decir, al interrumpir la anticoncepción, elevada ya a la altura de derecho a la salud reproductiva. Así, Kant explica (en un pasaje citado por Anne Fagot-Largeault) que el respeto a la persona humana no sólo implica deberes hacia el otro sino también deberes hacia nosotros mismos, empezando por el de mantenernos en vida al seguir alimentándonos y cuidándonos.

Por lo tanto hay más profundidad de lo que se podría pensar a primera vista en la reflexión de Bourgeois-Pichat que vincula la tendencia suicida de una sociedad con su libertad de acción y de autodestrucción, establecida en adelante como derecho humano. Para que la humanidad se reproduzca en las mejores condiciones, la solución no es limitar los derechos de la persona sino extenderlos, incluyendo entre nuestras razones de actuar la consideración de los derechos de las generaciones futuras que representan otros tantos deberes para la generación presente, como el deber de no imponerles una carga excesiva y de legarles un medio ambiente aceptable. Como explica Birnbacher, el problema es difícil pues no sólo se trata de cuidar los intereses de los seres cercanos que siguen inmediatamente a nosotros, sino de respetar obligaciones frente a una multitud lejana, compuesta por seres anónimos. Además, esa multitud no podrá ejercer ninguna sanción contra nosotros en caso de incumplimiento: nosotros nunca sufriremos por sus acciones, mientras que ellos podrán sufrir por las nuestras. Como corolario, si intentamos preservar sus intereses no podrán retribuirnos; deberemos actuar de manera desinteresada.

En esas condiciones, Birnbacher imagina que se podrían concretar los derechos de las generaciones futuras creando una función de me- 
diador o de ombudsman encargado de defenderlos en el más alto nivel, particularmente a escala europea. Piensa también en un trabajo pedagógico profundo para sensibilizar a las generaciones actuales en lo referente a sus obligaciones hacia las generaciones futuras. Repitamos lo que dijimos antes: tales acciones corren el riesgo de asimilarse a operaciones de inculcación, poco eficaces si no están acompañadas de acciones concretas, de tipo fiscal y jurídico, por ejemplo, que nos obliguen a invertir para el porvenir. Sin duda alguna, a la demografía le convendría asociarse más estrechamente con la temática del desarrollo duradero para completar ese trabajo de sensibilización. La advertencia de Jean Bourgeois-Pichat debe tener consecuencias.

\section{Conclusión: preferir el porvenir al futuro}

A modo de conclusión, se me permitirá un inciso lingüístico. En francés, la palabra "avenir" (porvenir) está desapareciendo en favor de la palabra "futur" (futuro). Decimos cada vez más "en el futuro" en vez de decir "en el porvenir". Parecería ser que el mismo fenómeno se presenta en español y en italiano, y sin duda por la misma razón, a saber, el éxito del sustantivo inglés future, fácil de aclimatar en nuestras lenguas en razón de su origen latino y del uso que ya hacemos de él en su forma adjetiva. Pero quizás haya una razón más profunda del rápido desplazamiento del porvenir en favor del futuro. El porvenir conlleva una fuerte carga de incertidumbre, mientras que el futuro parece seguro. El futuro será, mientras que el porvenir todavía está por venir. Además, no se dice (o todavía no se dice) que un joven o una joven tiene futuro, sino que tiene porvenir.

Me parece que el demógrafo debería preservar cuidadosamente esta carga de incertidumbre asociada a los tiempos por venir y no confundir el porvenir con el futuro. Debe abrir perspectivas, explorar varios escenarios, incluyendo aquellos que ponen de relieve la circulación de los seres humanos entre los continentes. No conformarse con vaticinar la catástrofe. Incluso cuando hace proyecciones, el lema del demógrafo debería ser "ni predicción ni predicación". En cambio, debe seguir trabajando con un sentimiento de responsabilidad creciente frente a las generaciones por venir. En eso reside, a mi parecer, la sustancia del mensaje que nos ha legado Bourgeois-Pichat. 